Full-text Available Online at www.ajol.info and www.bioline.org.br/ja

\title{
Effect of Cutting Fluids on the Flank Wear of High Speed and Carbide Tipped Cutting Tools
}

\section{*110; OSARENMWINDA}

\author{
Department of Production Engineering, University of Benin, Benin City, Nigeria. \\ Email:joosarenmwinda@yahoo.com
}

KEY WORDS: Flank wear, Cutting fluid. High speed steel, Carbide tipped tool, soluble oil.

\begin{abstract}
The major needs in machining are high material removal rate, good work surface finish and low tool wear. These objectives can be achieved by reducing tool wear using proper cutting fluid during machining.The effect of some cutting fluids namely: Mentholated spirit, paraffin, and soluble oil on the flank wear of High-speed steel and carbide tipped tools by orthogonal cutting has been studied. Cente lathe was used for cylindrical turning operated at a speed of 370rpm and depth of cut of $1 \mathrm{~mm}$ to machine aluminum, brass, mild steel and medium carbon steel workpiece. It was observed that soluble oil with $20 \%$ water concentration gave minimum flank wear among the cutting fluids used. The flank wear were $.0 .002 \mathrm{~mm}, 0.008 \mathrm{~mm}, 0.009 \mathrm{~mm}$ and $0.012 \mathrm{~mm}$ for soluble oils, mentholated spirit, paraffin and dry machining respectively cutting fluid using high speed Steel cutting tool and Aluminum workpiece. For the workpiece, aluminum gave minimum tool flank wear, followed by brass. mild Steel and Medium Carbon Steel respectively. Carbide tipped tool also exhibited better flank wear resistance than High speed steel. Soluble oil gave the minimum flank wear and best surface finish for all workplace and so have the capacity to give a longer tool life when compared with other cutting fluid studied. @ JASEM
\end{abstract}

\section{http://dx.doi.org/10.4314/jasem.v18 i2.2}

Introduction: The correct selection and use of cutting fluids is one of the most important and often one of the cheapest factors in enhancing the performance of cutting tools (Timings, 1997). In metal cutting process, the condition of the cutting tools plays a significant role in achieving consistent quality and also for controlling the overall cost of manufacturing. To obtain optimum rates of metal removal and at the same time maintain optimum tool service life, it is necessary to both lubricate and cool the chip / tool interface. Cutting fluids are designed to fulfill one or more of the following functions (Timings, 1997, Yildiz et al,2007,Vikram et al,2007)

To cool the tool and work piece. To lubricate the chips / tool interface 'and reduce tool wear due to friction and abrasion, To improve the finishing of the machined surface. Ta flush away the chips from the cutting zone. To prevent the corrosion of the work and machine. To prevent chip welding(formation of a built — up edge)

Cutting fluids reach the chip tool interface by a number of processes such as diffusing through the highly distorted structure of the metal in the chip and by capillary action.
Several authors have applied different methods to source lubricants for metal forming and machining (Avitzur, 1963; Babaagba, 1986; Cholakou and Rowe. 1982). Some of these tests include measurement of tool wear rate or tool life, determination of chip compression ratio and coefficient of friction, measurement of temperature and measurement of surface roughness, Husa (1957)

Yahya 2010 carried out an experimental iinvestigation on effect of cutting fluids in turning with coated carbides Tool.Flank wear, cutting force and surface roughness value were measured throughout the tool life and the results obtained compared with dry and wet-cooled turning. The results indicated substantial reduction in tool wear when wet cooled turning was applied, which enhanced the tool life,

Obi (1997) investigated the performance of local vegetable oils (i.e. ground-nut oil, palm oil, and cotton seed oil) as cutting fluid in orthogonal cutting of aluminum and brass using high speed steel cutting tool. His result which was based on surface quality and reduction on chip compression ratio showed that groundnut oil performed better in the machining of 
aluminum, while cotton seed oil showed a sparingly better performance than the rest in the machining of brass at all speeds tested.

Kurimoto and Barrow (1981) did a study on the influence of soluble -and straight cutting oils when turning alloy steel with high-speed steel tools. The results indicated that under practical cutting conditions, the straight oil did not penetrate the chip tool interface and hence did not exhibit a lubricating action, whilst the soluble oils showed considerable penetration.

Muktar and lbhadode (1999) formulated soluble oil from locally available materials. These materials were low-grade automotive oil. Emulsifying wax, ordinary washing soap and other additives. Report shows that it compared favourably with the commercial soluble oil The former has a maximum deviation of $4.2 \%$ flank wear over the latter when machining operation was carried out with center lathe at a feed of $0.15 \mathrm{~mm} / \mathrm{rev}$, and depth of cut of $02 \mathrm{~mm}$ using medium carbon steel work piece and high speed steel cutting tool.

The major needs in machining are high material removal rate, good work surface finish and low tool wear. These objectives can be achieved by reducing tool wear using proper cutting fluid during machining. This paper aims to determine the effect of cutting fluids on the flank wear of high-speed steel and carbide tipped cutting tools . It is hoped that this paper will assist in the selection of cutting fluids, cutting tools and workpiece for optimum cutting condition.

\section{METHODOLOGY}

Equipment and Materials: The equipment and materials are as follow: Center lathe, High speed steel and carbide tipped and cutting tool with $7^{\circ}$ clearance angle and $25^{\circ}$ rake angle, Tool markers microscope. Stopwatch Cylindrical mild steel, brass, aluminu.m and medium carbon steel workpiece of $50 \mathrm{~mm}$ diameter and $200 \mathrm{~mm}$ length workpiece. Mentholated spirit, paraffin, and soluble oil were the cutting fluids used.

Procedure: The lathe was set up for cylindrical turning with the high speed steel tool clamped to the tool post and the mild steel work piece fixed and held with the 3 jaw chuck. The centre lathe set at a speed of $370 \mathrm{rpm}$ was used for turning at $1 \mathrm{~mm}$ depth of cut. Machining was stopped after 120 seconds and the tool removed and its flank wear measured using the tool markers microscope. The cutting tool was then carefully reinserted and the dry machining procedure repeated for 240 seconds, 360 seconds .... and 1200 seconds. The corresponding flank wear was, determined and also recorded. The above procedure was repeated using soluble oil with $20 \%$ concentration in water, mentholated spirit and paraffin and their corresponding tool flank wear determined using tool markers microscope and also recorded for the aluminum, brass and medium carbon steel workpiece. The above procedure was repeated using carbide tipped cutting tool and the corresponding flank wear determined and recorded.

\section{RESULTS AND DISCUSSIONS}

Flank wear is a major form of tool wear in metal cutting.when machining using tools under typical condition, gradual wear of the flank of the flank is the main process by which a cutting tool fails ( Luo et al,2005; Haron,2001).

Figures 1-4 show the graph of flank wear (mm) against time (sec.) for several cutting fluids using high speed steel cutting tool and workpiece aluminum, brass, mild steel and medium carbon steel respectively. Figures 5-8 also show similar results using carbide tipped tool.

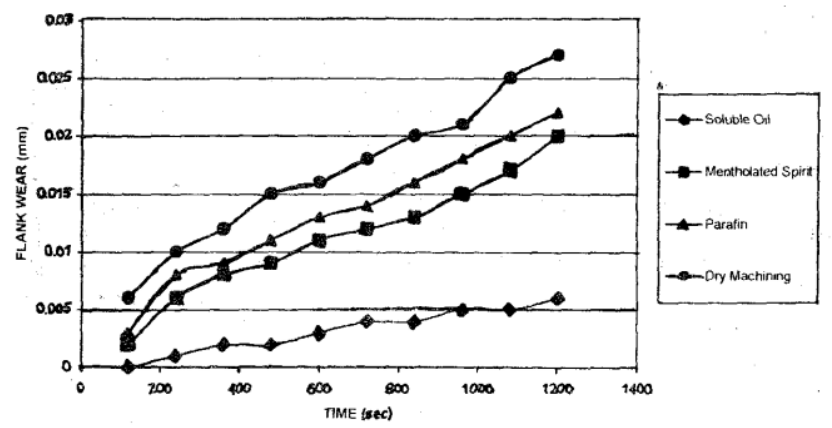

Fig 1: Graph of flank wear (mm against time (sec)with several cutting fluid with high speed steel cutting Tool and aluminum work piece 


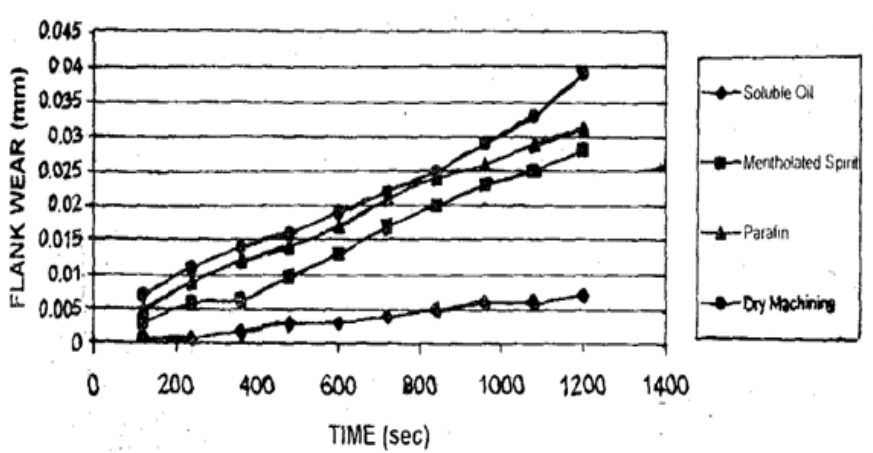

Fig. 2: Graph of flank wear (mm) against time (sec) with high speed steel cutting tool and brass workpiece
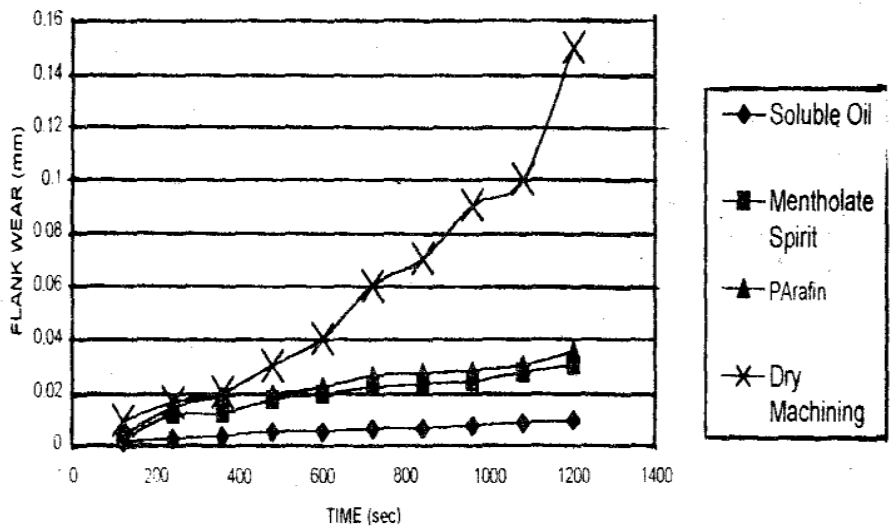

Fig. 4: Graph of flank wear (mm) against time (sec) with high speed steel cutting tool and medium carbon steel

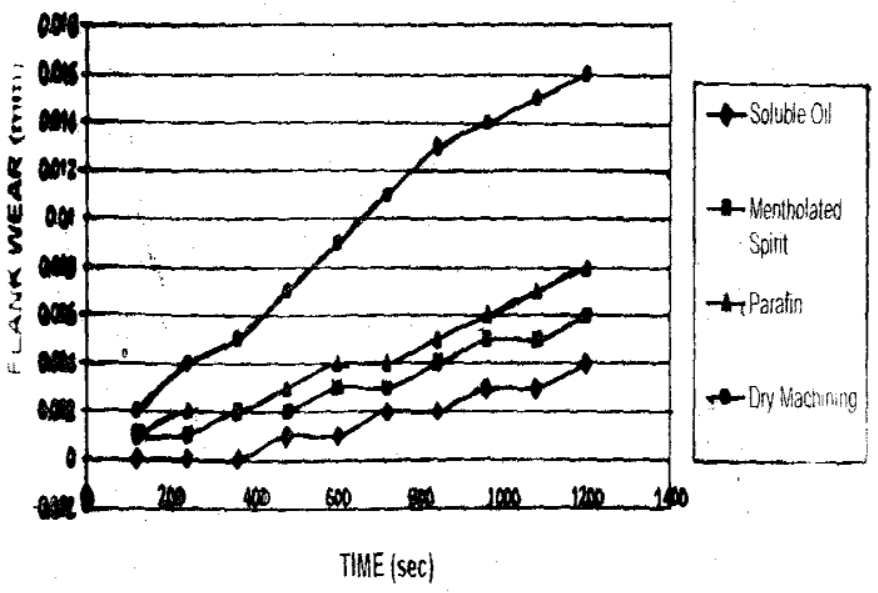

Fig. 6: Graph of flank wear (mm) against time (set) with carbide tipped tool and brass workpiece

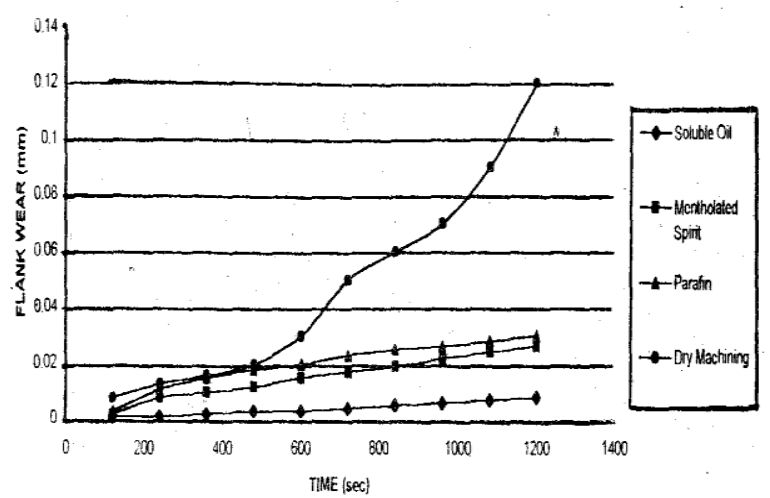

Fig.3: Graph of flank wear (mm) against 1 (sec) with high speed steel cutting tool and mild steel workpiece

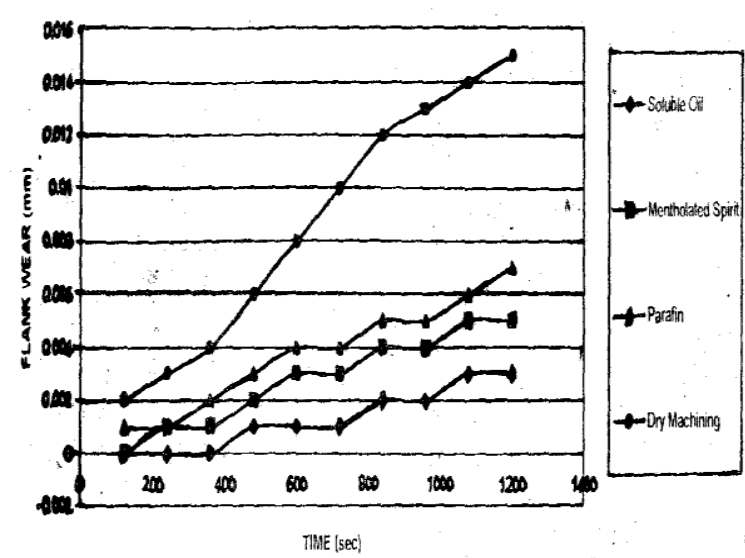

Fig.5: Graph of flank wear (mm) against time (see) with carbide tipped tool and aluminum wor piece

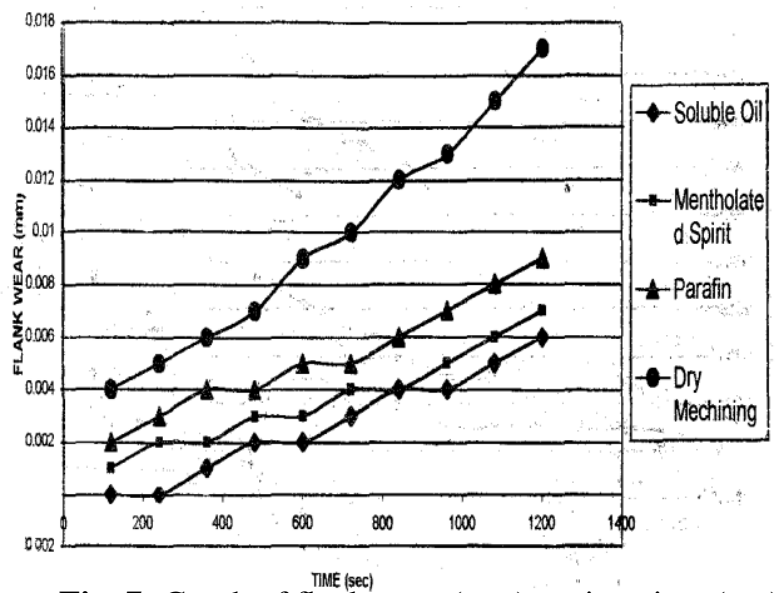

Fig. 7: Graph of flank wear (mm) against time (sec) with carbide tipped tool and mild steel workpiece 


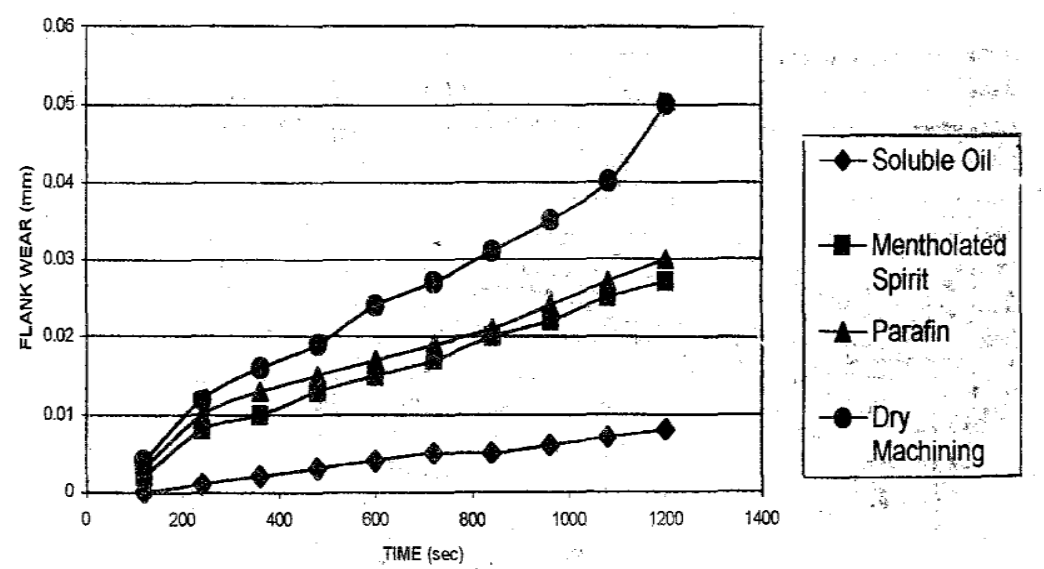

Fig. 8: Graph of flank wear ( $\mathrm{mm}$ ) against time (sec) with carried tipped tool and medium carbon steel

It was observed in Figures 1-8 that soluble oil with $20 \%$ water concentration gave minimum flank wear among the cutting fluid used.This was was followed by Mentholated spirit, paraffin and dry machining respectively. This results compare favourably with the obtained by Hamad et al,2014, when soluble oil gave the lowest flank wear and cutting force as compared to neat oil and synthetic cutting fluid when used for machining. For example, at a time of 360 seconds, Fig. 1 shows the flank wear were $.0 .002 \mathrm{~mm}$, $0.008 \mathrm{~mm}, 0.009 \mathrm{~mm}$ and $0.012 \mathrm{~mm}$ cutting fluids soluble oils, mentholated spirit, paraffin and dry machining respectively using high speed Steel cutting tool and Aluminum workpiece. The same trend was observed as shown in Figures 2-4 and Figures 5-8 where tipped carbide cutting tool was used. This values are lower than the flank wear values of $0.33 \mathrm{~mm}$ and $0.1 \mathrm{~mm}$ obtained by yahya, 2010 and Dhar et al,2001 respectively when carbide cutting tool was used.The reasons may be due to the different cutting conditions used and the fact that AISI 1060 steel workpiece is of a higher strength than workpiece evaluated and so will caues a higher flank wear rate (Timings, 1997).

It was also observed that aluminum workpiece gave minimum cutting tool flank wear for the two cutting tools used, followed by Brass, mild steel and medium carbon steel respectively. For example, after 1200 seconds, the flank wear for high speed steel cutting tool using soluble oil observed were $0.05 \mathrm{~mm}$, $0.007 \mathrm{~mm}, 0.008 \mathrm{~mm}$ and $0.009 \mathrm{~mm}$ for Aluminum Brass, mild steel and medium carbon steel workpiece respectively. Using also carbide tipped tool, the flank wear after 1200 seconds with soluble oil cutting fluids were $0.003 \mathrm{~mm}, 0.004 \mathrm{~mm}, 0.006 \mathrm{~mm}$ and $0.008 \mathrm{~mm}$ for aluminum, brass, mild steel and medium carbon steel workpiece respectively. The same trend was observed for all the other cutting fluids used. Comparing the two cutting tools used, it was observed that the carbide tipped tool gave a lower flank wear than the High- speed steel.. For example from Figs. 1-8, the flank wear after 1200 seconds using mild steel workpiece and soluble oil was $0.006 \mathrm{~mm}$ and $0.008 \mathrm{~mm}$ for carbide tipped cutting tool and High speed steel cutting tool respectively. Also, using mentholated spirit as cutting fluid, the flank wear after 1200 seconds using brass workpiece was $0.004 \mathrm{~mm}$ and $0007 \mathrm{~mm}$ respectively. This shows that carbide tipped tool is stronger, tougher and has higher wear resistance properties than High-speed steel. Soluble oil gave best surface finish for all workplace. Good surface finish was also produced when paraffin was used on aluminum workpiece.

Conclusions: Cutting tools flank wear under several cutting fluids have been examined by orthogonal cutting using center lathe. Soluble oil with 20\% concentration in water concentration gave minimum flank wear. Aluminum workpiece also produced the minimum cutting tool flank wear followed by Brass, mild steel and medium carbon steel respectively. Carbide tipped tool showed better flank wear resistance than High-speed steel tool used. It is hoped that this paper will assist in the choice and selection of cutting tools, cutting fluids and materials to obtain optimum results for machining. 


\section{REFERENCES}

Avitzur, B. (1963): Analysis of Wire Drawing and Extrusion Conical Dues of Small Curve Angles. Journal of Engineering for Industry, Trans ASME, Series B, 85: 89-96.

Babaagba, R. S. (1986): Evaluation of Local Oil as Lubricants in Deep Drawing Operations, MSc Thesis. Department of Chemistry, Ahmadu Bello University, Zaria, Nigeria.

Cholakou, C. S; Rowe, C. W. (1992): Lubricating Properties of Grinding Fluids II - Comparison of Fluids in Four Ball Tribometer Test, WEAR. 155: $331-342$.

Dhar, N.R; Bhowmic, T.P; Chattopadhyay, A.B (2001) The influence of cutting fluids on the wear characteristics and life of carbide cutting tools. International conference on mechanical engineering,December 26-

28,2001dhaka,bangladesh pp VI 73-77

Hamdan, .A;Fadzil,K.A; Abou-El-Hossein; Hamdi M. (2014) performance evaluation of different types of cutting fluid in the machining of AISI hardened steel using pulsed jet minimal quantity lubrication sysytem.invited paper .wwwseed.net.org/download

Haron, C.H.C.; Ginting, A.; Goh, J.H.(2001) Wear of coated and uncoated carbides in turning tool steel, Journal of Materials Processing Technology, .116: 49-54.

Husa, H. W. (1957): Cutting Fluid Evaluation, Trans ASME. 79: 1143-1172.
Kurjmóto, T; Barrow G. (1981): The Wear of High Speed Steel Cutting Tools under the Action of Several Different Cutting Fluids. Proceeding of the Twenty-Second International Machine Tool Design Research Conference, Manchester,: 237 -246 .

Luo, X;, Cheng, K.; Holt, R; Liu, X(2005) Modeling flank wear of carbide tool insert in metal cutting, Wear, 259:.1235-1240.

Muktar, M.; lbhadode, A .O. A. (1999): Effects of Cutting Fluids on Tool Wear during Turning Operation, NSE Technical Transactions, . 34( 4): $64-75$.

Obi, A. I. (1991): Use of Local oil as Cutting Fluids for Aluminum and Brass. Nigerian Journal of Technical Education, 14(.2):.98-111.

Timings, R. L. (1997): Manufacturing Technology, Vol. 2, Addison Wesley Longman Limited, Edinburgh, England.

Vikram Kumara, C. R.; Ramamoorthy, B.(2007) Performance of coated tools during hard turning under minimum fluid application, Journal of Materials Processing Technology,. 185: 210-216.

Yahya, Isik,(2010).An Experimental Investigation on Effect of Cutting Fluids in Turning with Coated Carbides Tool. Journal of Mechanical Engineering. .56: 1-7

Yildiz, Y; Gunay, M.; Seker, U. (2007)The effect of the cutting fluid on surface roughness in boring of low carbon steel-technical communication, Machining Science and Technology, 11: 553560. 